\title{
Genomic and evolutionary aspects of phytoplasmas
}

\section{Kenro Oshima*, Kensaku Maejima and Shigetou Namba*}

Department of Agricultural and Environmental Biology, Graduate School of Agricultural and Life Sciences, The University of Tokyo, Yayoi, Bunkyo-ku, Tokyo, Japan

\section{Edited by:}

Hiromi Nishida, Toyama Prefectural University, Japan

\section{Reviewed by:}

Hee-Young Jung, Kyungpook National University, South Korea

Assunta Bertaccini, DipSA Alma

Mater Studiorum University of

Bologna, Italy

\section{*Correspondence:}

Kenro Oshima and Shigetou Namba, Department of Agricultural and

Environmental Biology, Graduate

School of Agricultural and Life Sciences,

The University of Tokyo, 1-1-1 Yayoi,

Bunkyo-ku, Tokyo 113-8657, Japan

e-mail:kenro@ims.u-tokyo.ac.jp;

anamba@mail.ecc.u-tokyo.ac.jp
Parasitic bacteria that infect eukaryotes, such as animals and plants, often have reduced genomes, having lost important metabolic genes as a result of their host-dependent life cycles. Genomic sequencing of these bacteria has revealed their survival strategies and adaptations to parasitism. Phytoplasmas (class Mollicutes, genus 'Candidatus Phytoplasma') are intracellular bacterial pathogens of plants and insects and cause devastating yield losses in diverse low- and high-value crops worldwide. The complete genomic sequences of four Candidatus Phytoplasma species have been reported. The genomes encode even fewer metabolic functions than other bacterial genomes do, which may be the result of reductive evolution as a consequence of their life as an intracellular parasite. This review summarizes current knowledge of the diversity and common features of phytoplasma genomes, including the factors responsible for pathogenicity.

Keywords: phytoplasma, genome, mycoplasma, reductive evolution, ATP synthase, secreted protein, virulence factor

\section{INTRODUCTION}

Phytoplasmas (genus 'Candidatus Phytoplasma') are plant pathogens of the bacterial class Mollicutes (Lee etal., 2000; Hogenhout et al., 2008). Phytoplasmas lack rigid cell walls, are surrounded by a single membrane, and are spherical or pleiomorphic with sizes similar to those of mycoplasmas $(80-800 \mathrm{~nm}$; Figure 1); therefore, phytoplasmas were called mycoplasma-like organisms upon their discovery in 1967 (Doi et al., 1967). Sequence analysis of 16S rRNA and other housekeeping genes suggest that phytoplasmas are members of the class Mollicutes but are more closely related to the Acholeplasma spp. than to the Spiroplasma spp. or animal mycoplasmas (Lim and Sears, 1992; Namba et al., 1993; Oshima and Nishida, 2007). Phytoplasmas are transmitted by insect vectors and infect over 700 plant species, including many economically important crops such as fruit trees and ornamental plants (Bertaccini, 2007). Infected plants show a wide range of symptoms, including stunting, yellowing, witches' broom (proliferation of shoots), phyllody (formation of leaf-like tissues instead of flowers; Figure 2), virescence (greening of floral organs), proliferation (growth of shoots from floral organs), purple top (reddening of leaves and stems), and phloem necrosis (Hogenhout et al., 2008).

Phytoplasma infection is often fatal and causes devastating damage to agricultural production around the world. For example, phytoplasmal epidemics among coconut palms have destroyed the livelihoods of many people in Africa and the Caribbean, who depend on the trees for nourishment, building materials, and income (Strauss, 2009). In 2001, a phytoplasma outbreak in apple trees caused a loss of about $€ 100$ million in Italy (Strauss, 2009). In addition, phytoplasma-related diseases are expected to increase because global warming/climate change is advantageous to the cold-sensitive phytoplasma vectors (Hogenhout et al., 2008). Therefore, the development of phytoplasma pest control methods will become more important in the future.
Phytoplasmas parasitize the phloem tissues of infected plant hosts and are transmitted by insect vectors (mostly leafhoppers; Christensen et al., 2005; Hogenhout et al., 2008). After infecting an insect, the bacteria traverse the wall of the intestinal tract, multiply in the hemolymph, pass through the salivary glands, and multiply further. When the infected insect feeds on a new host plant, the phytoplasmas are introduced into the phloem tissue along with salivary fluids.

Although the unique features of phytoplasmas have long made them a subject of interest, the difficulty of in vitro culture has hindered their molecular characterization. In the past decade, whole genome sequences have been completed for several phytoplasma strains (Figure 3; Oshima et al., 2004; Bai et al., 2006; Kube et al., 2008; Tran-Nguyen et al., 2008), enabling better understanding of the molecular mechanism underlying virulence and host interaction (Suzuki et al., 2006; Oshima et al., 2007, 2011; Hoshi et al., 2009). In this review, we summarize the history and recent progress in phytoplasma research from genomic and evolutionary perspectives.

\section{UNIQUE FEATURES OF PHYTOPLASMA GENOMES}

To characterize the genomic features of phytoplasma, several genome projects were begun all over the world in the 1990s and some genomic fragments have been cloned (Miyata et al., 2002, 2003; Oshima et al., 2002). The complete genomic sequence of 'Ca. P. asteris' OY-M strain was first determined in 2004 (Oshima et al., 2004); since then, the complete genomic sequences of ' $\mathrm{Ca}$. P. asteris' AY-WB strain, ' $\mathrm{Ca}$. P. australiense' and ' $\mathrm{Ca}$. P. mali' have been reported (Bai et al., 2006; Kube et al., 2008; Tran-Nguyen et al., 2008). In general, a phytoplasma genome consists of one chromosome and several small plasmids with a unique replication gene (Nishigawa et al., 2001; Oshima et al., 2001a; Firrao et al., 2007), although ' $\mathrm{Ca}$. P. mali' harbors no plasmids (Kube et al., 2012). The phytoplasma chromosome size is $600-880 \mathrm{~kb}$, which 


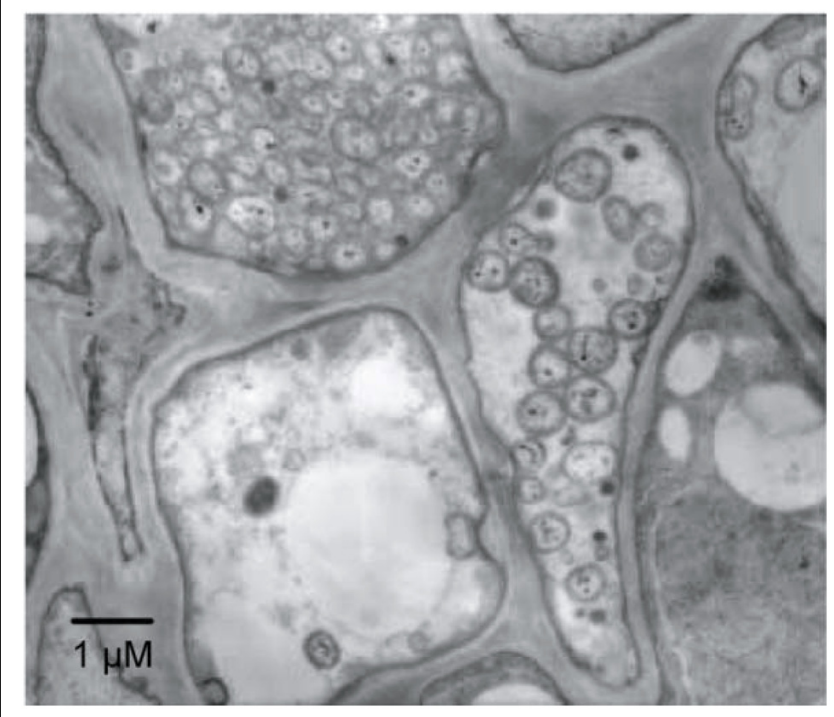

FIGURE 1 | Electron microphotograph of Candidatus Phytoplasma asteris infecting the plant phloem. A section of phloem tissue from an infected plant vascular bundle is shown. Several of the plant cells contain phytoplasma cells.

is quite small in comparison to those of other plant pathogens but similar to those of mycoplasmas (Figure 4). Phytoplasma genomes have a low $\mathrm{G}+\mathrm{C}$ content (21-28\%), similar to mycoplasmas (Glass et al., 2000) and endosymbiotic bacteria (Tamas et al., 2002; Wernegreen, 2002). Since the small genomes of parasitic and/or symbiotic bacteria are comprised mostly of functional genes, comparisons of the metabolic pathways in these organisms often reveal fundamental divergences in the microbial way of life and their evolutionary origins (Moran, 2002). In general, smallgenome pathogenic bacteria have lost the genes for numerous biosynthetic pathways, most likely because many metabolites are available within the host cell environment; this reduces the selective constraints on genes for biosynthetic capabilities. In addition, selection favoring the loss of factors such as microbe/pathogenassociated molecular patterns (MAMPs or PAMPs) that may trigger host responses (Jones and Dangl, 2006) is another likely explanation for gene loss events, especially for phytoplasmas that must navigate between two diverse hosts (Hogenhout et al., 2008).

Although the phytoplasma genome contains genes for basic cellular functions such as DNA replication, transcription, translation, and protein translocation (Kakizawa et al., 2001; Jung etal., 2003), it has lost many metabolic genes. In general, mycoplasmas lack genes for the tricarboxylic acid cycle, sterol biosynthesis, fatty acid biosynthesis, de novo nucleotide synthesis, and biosynthesis of most amino acids; thus, they must depend entirely on their host to supply them with the products of these pathways (Razin et al., 1998). Similarly, no genes for these biosynthetic pathways have been identified in phytoplasmas. However, the phytoplasmas have lost more metabolic genes than the mycoplasmas (Oshima et al., 2004; Bai et al., 2006), including those of the pentose phosphate pathway. Instead, phytoplasmas

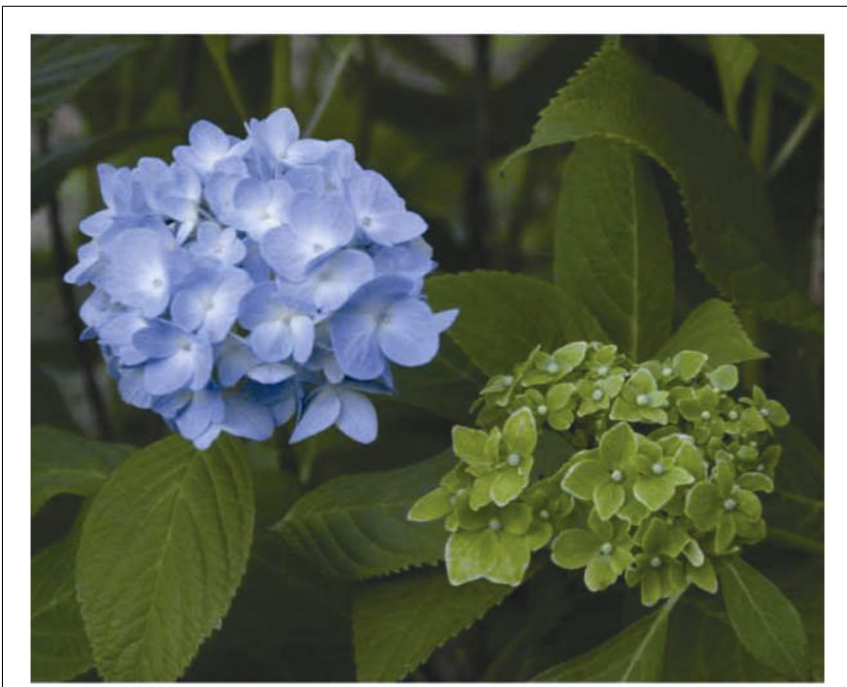

FIGURE 2 |Typical symptoms in a phytoplasma-infected hydrangea (right), called "phyllody". A healthy flower is shown on the left.

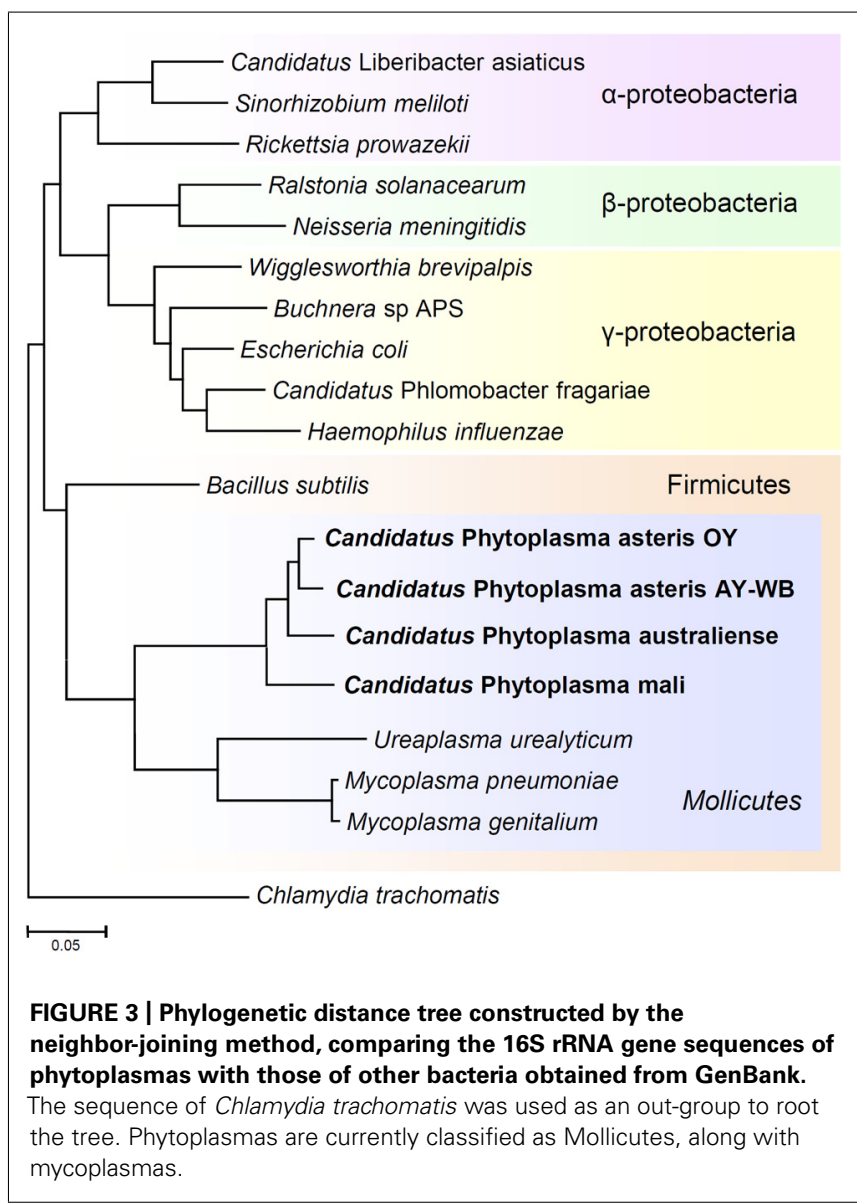

harbor multiple copies of transporter-related genes that are not found in mycoplasmas (Oshima et al., 2004). These genomic features suggest phytoplasmas are highly dependent on metabolic compounds from their host. 


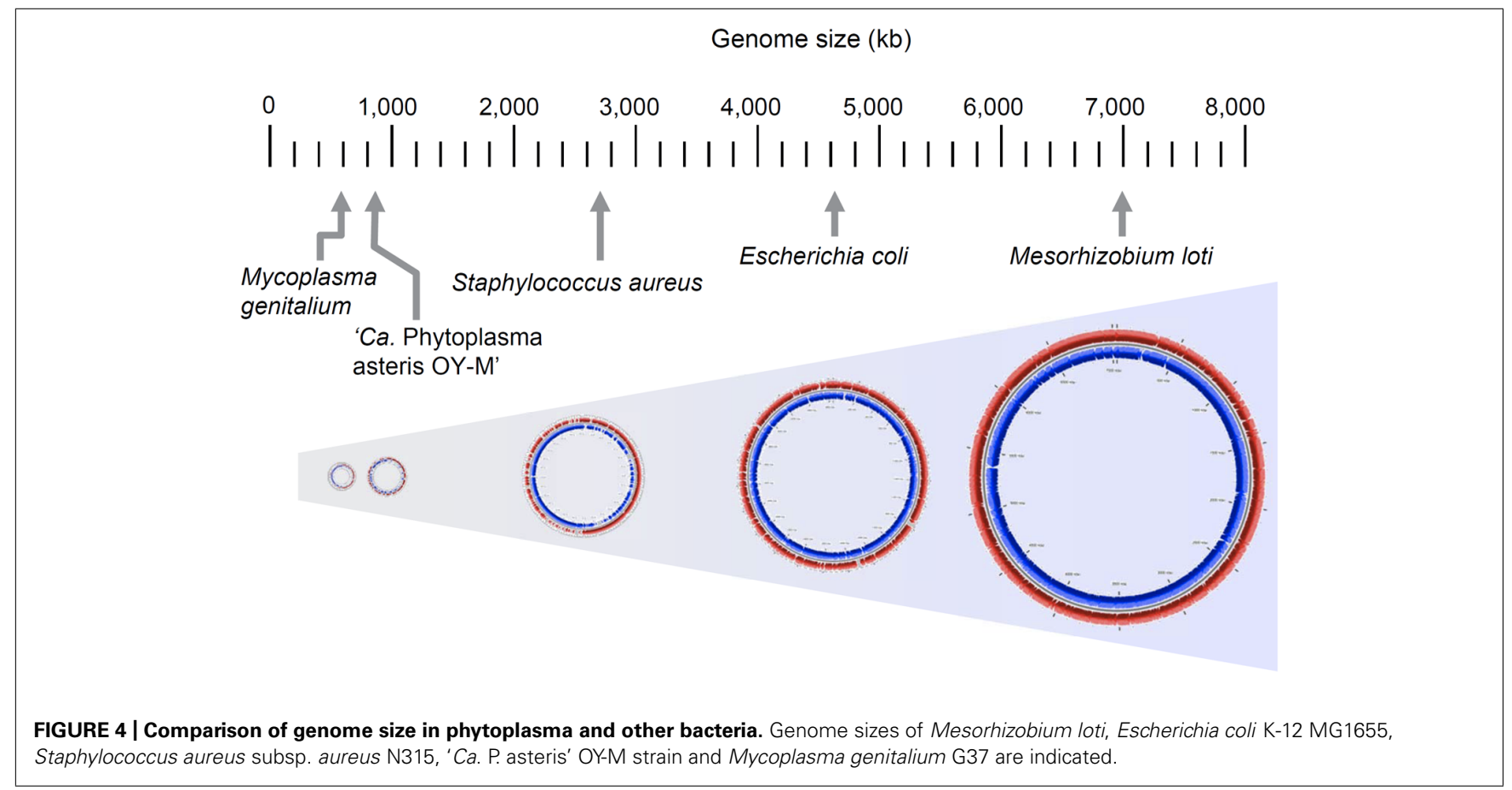

\section{ABSENCE OF THE $F_{1} F_{0}$-TYPE ATP SYNTHASE}

The most unique feature of the phytoplasma genome may be the absence of the gene encoding $\mathrm{F}_{1} \mathrm{~F}_{\mathrm{o}}$-type ATP synthase. In general, bacteria use $\mathrm{F}_{1} \mathrm{~F}_{\mathrm{O}}$-type ATP synthases to synthesize and hydrolyze ATP using ATP-proton motive force interconversion. Like other eubacteria, mycoplasmas also possess an $\mathrm{F}_{1} \mathrm{~F}_{\mathrm{O}}$-type ATP synthase (Razin et al., 1998); however, no genes for an $\mathrm{F}_{1} \mathrm{~F}_{\mathrm{o}}$-type ATP synthase have been identified in the four sequenced phytoplasmas (Oshima et al., 2004; Bai et al., 2006), suggesting these genes may have been lost. Since the genes encoding ATP synthase have been found in most fully sequenced bacteria, ' $\mathrm{Ca}$. P. asteris' OY-M strain was the first example of a naturally occurring organism with no ATP synthase genes (Oshima et al., 2004).

Despite the absence of an ATP synthase gene, there is considerable membrane potential in phytoplasmas, as has been demonstrated with potentiometric dye (Christensen et al., 2004). Phytoplasmas have five genes encoding P-type ATPases, which are similar to animal $\mathrm{Na}^{+} / \mathrm{K}^{+}$and $\mathrm{H}^{+} / \mathrm{K}^{+}$pumps (Bai et al., 2006), implying that these ATPases may generate electrochemical gradients across the membrane (Christensen et al., 2005).

\section{GLYCOLYTIC PATHWAY}

In light of a previous report showing that glycolytic turnover increases in Bacillus subtilis strains in which the atp operon has been deleted (Santana et al., 1994), ATP synthesis in phytoplasma is likely to be strongly dependent on the glycolytic pathway. Dependence on the glycolytic pathway is also supported by sequencing analysis of ca. 80-kb genomic DNA from ' $\mathrm{Ca}$. P. asteris' OY-W strain, which causes severe symptoms (Oshima et al., 2001b). Interestingly, an approximately $30-\mathrm{kb}$ region was found to be tandemly duplicated in the ' $\mathrm{Ca}$. P. asteris' OY-W strain genome (Oshima et al., 2007). Two sets of five glycolytic enzymes were encoded in this genomic region, which is a unique gene structure not identified in any other bacterial genomes. The gene organization of glycolytic genes of ' $\mathrm{Ca}$. P. asteris' AY-WB strain (Bai et al., 2006) is similar to that of ' $\mathrm{Ca}$. P. asteris' OY-M strain rather than ' $C a$. P. asteris' OY-W strain, suggesting the duplication of glycolytic genes was specific to ' $\mathrm{Ca}$. P. asteris' OY-W strain.

Glycolysis seems to be an important metabolic pathway in phytoplasmas, although the genes for glycolysis are completely absent in ' $\mathrm{Ca}$. P. mali' (Kube et al., 2008), which instead carries the gene for 2-dehydro-3-deoxyphosphogluconate aldolase (eda; Kube et al., 2012), unlike the other three sequenced phytoplasma strains. An alternative metabolic pathway has been hypothesized in ' $\mathrm{Ca}$. P. mali', in which pyruvate is formed independently from glycolysis (Kube et al., 2012). Further studies are needed to elucidate the energy-yielding systems of phytoplasmas.

\section{DIVERSITY AND COMMON FEATURES OF METABOLIC GENES}

Phytoplasma genomes are highly diverse in genome structure and content (Figure 5; also reviewed in Kube et al., 2012). The uptake of carbohydrate from host cells is an important feature of phytoplasma. Sucrose seems to be an ideal carbon source for bacteria inside a plant, as the highest concentrations of sucrose (200-1,600 mM) are found in the sieve tubes. A gene for sucrose phosphorylase (amyA, synonym sucP or $g t f A$ ), which cleaves sucrose into glucose and fructose, was identified in the ' $\mathrm{Ca}$. $\mathrm{P}$. australiense' genome. The amyA gene was also identified in the ' $\mathrm{Ca}$. P. asteris' OY-M strain genome; however, as it contains a mid-sequence frameshift mutation leading to an early termination codon, the expected ORF is incomplete and is divided into two smaller ORFs (Oshima et al., 2004), suggesting that an ancestral phytoplasma may have possessed a functional copy of this gene. In 




contrast, the 'Ca. P. mali' and ' $\mathrm{Ca}$. P. asteris' AY-WB strain genomes do not harbor amyA (Figure 5). These findings suggest utilization of carbon sources may differ between phytoplasma species.

Although metabolic genes are reduced, phytoplasma genomes encode several genes necessary for folate biosynthesis. Four genes involved in folate biosynthesis ( folk, folP, folC, and folA) are encoded in the ' $\mathrm{Ca}$. P. asteris' OY-M strain genome. In contrast, only folA is encoded in the ' $\mathrm{Ca}$. P. mali' and ' $\mathrm{Ca}$. P. australiense' genomes. In the ' $\mathrm{Ca}$. P. asteris' AY-WB strain genome, the folA gene is complete, but folk and folP are pseudogenes (Figure 5). This diversity in gene content suggests that at least four genes for folate biosynthesis may have been encoded in an ancestral phytoplasma genome but were gradually eliminated in the course of its reductive evolution.

Although no genes for de novo synthesis of nucleotides are encoded in the phytoplasma genomes, they do contain genes for salvage pathways of purine and pyrimidine metabolism, more similar to Rickettsia than mycoplasmas (Oshima et al., 2004). Gene content associated with purine and pyrimidine metabolism also differs between phytoplasma species. The gene for cytidine/uridine kinase is encoded in ' $\mathrm{Ca}$. P. asteris' OY-M strain and ' $\mathrm{Ca}$. P. asteris' $\mathrm{AY}-\mathrm{WB}$ strain but not in ' $\mathrm{Ca}$. P. mali' or ' $\mathrm{Ca}$. P. australiense.' Interestingly, only ' $\mathrm{Ca}$. P. asteris' AY-WB strain possesses the gene for cytosine deaminase ( $\operatorname{cod} A$; Figure 5$)$.

In contrast to the diversified energy metabolic genes, all four phytoplasma genomes contain the sodA gene (Figure 5), which encodes Mn-SOD, a protein that can inactivate reactive oxygen species (ROS; Miura etal., 2012). Plants deploy a broad range of defenses during infection by various pathogens. The oxidative burst, which produces ROS, is one of the earliest events in the plant defense response. Since the genomes of mycoplasmas do not contain this gene, the presence of $\operatorname{sodA}$ may help phytoplasmas 
defend themselves against the unique threat of ROS released by the plant cell.

\section{POTENTIAL MOBILE UNITS IN PHYTOPLASMA GENOMES}

Intriguingly, phytoplasma genomes contain clusters of repeated gene sequences, named potential mobile units (PMUs; Bai et al., 2006) or sequence-variable mosaics (SVMs; Jomantiene and Davis, 2006; Jomantiene et al., 2007; Wei et al., 2008). PMUs and SVMs have similar compositions and contain similar genes; henceforth, these gene clusters have been referred to as PMUs in this review. In the ' $\mathrm{Ca}$. P. asteris' AY-WB strain genome, PMUs are $\sim 20 \mathrm{~kb}$ in size and consist of genes with similarities to $s i g F, h f l B, d n a G$, $d n a B, t m k, s s b$, himA, and the IS3 family insertion sequence tra5, organized in a conserved order (Bai et al., 2006). These genes are also found in multiple copies, singly or in clusters, in other phytoplasma genomes (Oshima et al., 2004; Lee et al., 2005; Jomantiene and Davis, 2006; Jomantiene et al., 2007; Arashida et al., 2008). The repeated presence of PMUs, their gene contents, including genes for recombination (tra5, ssb, himA) and replication (dnaG, dnaB), and their conserved gene order suggests the PMUs are replicative composite transposons (Bai et al., 2006; Arashida et al., 2008). The PMU exists as linear chromosomal and circular extrachromosomal elements in ' $\mathrm{Ca}$. P. asteris' AY-WB strain (Toruno et al., 2010), suggesting that it has the ability to transpose within the genome. The presence of multiple PMUs or apparently degenerated PMU-like sequences, such as SVMs, and the dramatic loss of basic metabolic pathways in phytoplasma genomes (Oshima et al., 2004; Bai et al., 2006) suggest PMUs are likely to be important for phytoplasma fitness.

\section{PROTEIN SECRETION}

Since phytoplasmas have no cell wall and reside inside of host cells, their membrane proteins and secreted proteins function in the cytoplasm of the host plant or insect cell, and are predicted to have important roles in host-parasite interactions and/or virulence. Thus, the identification of both a secretion system and secreted proteins in phytoplasma genomes is important for understanding the biology of phytoplasmas. Phytoplasmas possess two secretion systems, the YidC system for the integration of membrane proteins, and the Sec system for the integration and secretion of proteins into the host cell cytoplasm.

The Sec protein translocation system is essential for viability in many bacteria (Economou, 1999; Tjalsma et al., 2000). The Escherichia coli Sec system, which is composed of at least 11 proteins and 1 RNA species, is the well-characterized Sec system (Economou, 1999). Among these proteins, SecA, SecY, and SecE are essential for protein translocation and cell viability in E. coli (Economou, 1999), and protein translocation activity can be reconstituted in vitro with only these three proteins (Akimaru etal., 1991). Genes encoding SecA, SecY, and SecE have been identified in the ' $\mathrm{Ca}$. P. asteris' OY-M strain genome, the (Kakizawa et al., 2001, 2004), and SecA expression has been confirmed in phytoplasma-infected plants (Kakizawa etal., 2001; Wei et al., 2004). These genes have also been identified in three other phytoplasma genomes (Bai et al., 2006; Kube et al., 2008; Tran-Nguyen et al., 2008), and $\sec Y$ genes have been cloned from many phytoplasma strains (Lee et al., 2006). These results strongly suggest that a functional Sec system is common among phytoplasmas.

Antigenic membrane protein (Amp), a major surface membrane protein of phytoplasmas (Barbara et al., 2002), has been reported to be a substrate of the Sec system. Amp has a Sec signal sequence at its N-terminus, which is cleaved in ' $\mathrm{Ca}$. $\mathrm{P}$. asteris' OY-M strain (Kakizawa et al., 2004), suggesting that the phytoplasma Sec system utilizes recognition and cleavage of a signal sequence, as in other bacterial Sec systems. This finding also suggests that signal sequence prediction programs, such as SignalP (Nielsen et al., 1997) or PSORT (Nakai and Kanehisa, 1991), may be applicable to phytoplasmal proteins and could be used to identify secretory proteins (Kakizawa et al., 2004). Several studies were performed to identify phytoplasma secretory proteins in their genome sequences, as given below.

YidC mediates integration of newly synthesized membrane proteins (Dalbey and Kuhn, 2000). Initially, YidC was found to co-purify with components of the Sec system (Scotti et al., 2000), and it was thought that YidC functions with the Sec system to insert transmembrane proteins into the lipid bilayer (Urbanus et al., 2001). However, YidC is sufficient to promote insertion of membrane proteins in vitro, suggesting its function is independent of the Sec system (Serek et al., 2004). YidC is encoded in all four completed phytoplasma genomes (Oshima et al., 2004; Bai et al., 2006; Kube et al., 2008; Tran-Nguyen et al., 2008); thus, phytoplasmas should have a YidC integration system. YidC is an essential protein in E. coli (Samuelson et al., 2000) and may also play an important role in phytoplasmas.

\section{PHYTOPLASMA VIRULENCE FACTORS}

Many gram-negative pathogens of plants and animals possess Type III secretion systems (T3SSs) that can inject bacterial virulence "effector" proteins into host cells (Cornelis and Van Gijsegem, 2000). They are important for the pathogenicity of Pseudomonas, Xanthomonas, Ralstonia, Erwinia, and Pantoea. T3SSs and flagella are evolutionarily related and share a remarkably similar basal structure. T3SSs and flagella are restricted to gram-negative bacteria, and the gram-positive phytoplasmas therefore possess no T3SSs.

Since membrane and secreted proteins are potential virulence factors, the phytoplasma genomes have been mined for the presence of these proteins. Among the secreted proteins of ' $\mathrm{Ca}$. P. asteris' OY-M strain, TENGU has been reported to induce symptoms similar to phytoplasma infection, including witches' broom (development of numerous shoot branches) and dwarfism (Hoshi et al., 2009; Sugawara et al., 2013). TENGU encodes a very small protein $(4.5 \mathrm{kDa})$. The mature protein, after cleavage of the $\mathrm{N}$-terminal signal peptide, is only 38 amino acids in length. Microarray analyses revealed that the expression of many auxinrelated genes was significantly downregulated in tengu-transgenic plants, suggesting that TENGU suppresses auxin signaling or biosynthesis pathways (Hoshi et al., 2009; Denancé et al., 2013). It has been also reported that phytoplasma-infected periwinkles can show remission of disease symptoms when cultured in medium containing a high-concentration of auxin (Pertot et al., 1998; Curkovic Perica et al., 2007). Thus, auxin may have a great impact on the plant-phytoplasma interaction. 
In the ' $\mathrm{Ca}$. P. asteris' $\mathrm{AY}-\mathrm{WB}$ strain genome, more than 56 genes encode predicted secreted proteins (Bai et al., 2009). Among them, SAP11 contains eukaryotic nuclear localization signals and localizes in plant cell nuclei (Bai et al., 2009). SAP11-expressing plants exhibit crinkled leaves and produce many stems (Sugio et al., 2011a). Moreover, the fecundity of insect vectors was increased on SAP11-expressing versus normal plants (Sugio et al., 2011a). Thus, phytoplasma-secreted proteins may manipulate the host and mediate virulence, similar to the findings seen for other pathogens (Higgins, 2001; Boutareaud et al., 2004). In addition to SAP11, SAP54 of ' $\mathrm{Ca}$. P. asteris' AY-WB strain was reported to cause morphological changes in Arabidopsis thaliana flower organ development, similar to the symptoms observed in phytoplasmainfected plants (MacLean etal., 2011). Although the molecular mechanisms remain unknown, it is assumed that proteins secreted by phytoplasmas may interfere with the function of genes involved in flower development (Sugio et al., 2011b; Sugio and Hogenhout, 2012).

Researchers believed phytoplasma disease symptoms are caused by the side effects of infection (indirect effects), such as the consumption of metabolites of infected plants. This idea was partially supported by the absence of many metabolic pathways and metabolite synthesis, as well as the retention of transporter genes to absorb metabolites and nutrients from the host cytoplasm (Oshima et al., 2004, 2007). However, the identification of TENGU, SAP11, and SAP54 clearly changed this idea: phytoplasma could aggressively induce symptoms by secretion of effector proteins and modification of plant-gene activity (Hoshi et al., 2009; Sugio et al., 2011a; Himeno et al., 2011). Therefore, additional searches for effector proteins in phytoplasma genomes would be useful.

\section{TRANSCRIPTIONAL CHANGES DURING HOST SWITCHING BETWEEN PLANT AND INSECT}

Since phytoplasmas are intracellular parasites of both plants and insects (Christensen et al., 2005), their ability to adapt to two diverse environments is of considerable interest. Microarray analysis of ' $\mathrm{Ca}$. $\mathrm{P}$. asteris' OY-M strain revealed that expression of approximately $33 \%$ of the genes changes during host switching between plant and insect, suggesting phytoplasma dramatically alters gene expression in response to its host (Oshima etal., 2011) and may use transporters,

\section{REFERENCES}

Akimaru, J., Matsuyama, S. I., Tokuda, H., and Mizushima, S. (1991). Reconstitution of a protein translocation system containing purified SecY, SecE, and SecA from Escherichia coli. Proc. Natl. Acad. Sci. U.S.A. 88, 6545-6549. doi: 10.1073/pnas.88. 15.6545

Arashida, R., Kakizawa, S., Hoshi, A., Ishii, Y., Jung, H. Y., Kagiwada, S., et al. (2008). Heterogeneic dynamics of the structures of multiple gene clusters in two pathogenetically different lines originating from the same phytoplasma.

secreted proteins, and metabolic enzymes in a host-specific manner.

The genes encoded in the PMU of ' $\mathrm{Ca}$. P. asteris' AY-WB strain are more highly expressed in insects than in plants (Toruno et al., 2010), most likely due to increased production of the extrachromosomal circular type of PMU during insect infection (Toruno et al., 2010). Differential gene expression between plant and insect hosts has been also reported in ' $\mathrm{Ca}$. P. asteris' OY-M strain, in which TENGU is more highly expressed in plant hosts than in insect hosts (Hoshi et al., 2009). As phytoplasmas reside within the host cell, secreted proteins are thought to play crucial roles in the interplay between pathogen and host cell. Therefore, the expression of virulence factors might be strictly regulated.

\section{FUTURE STUDY}

Analysis of the phytoplasma genome revealed not only the reductive evolution as a consequence of its life as an intracellular parasite but also the virulence factors that induce symptoms unique to phytoplasma diseases. Further analysis of phytoplasma genomes will improve our understanding of these economically important and biologically attractive microorganisms.

Phytoplasmas cause various disease symptoms including witches' broom, dwarfism, proliferation, phyllody, virescence, flower sterility, bolting, purple tops, generalized yellowing, and phloem necrosis (Bertaccini, 2007; Hogenhout et al., 2008). Three virulence factors have been identified, and the glycolytic pathway has been associated with some symptoms; however, not all phytoplasma disease symptoms could be explained by these virulence factors and pathways. The most probable candidates would be secreted proteins, so further functional analyses of secreted proteins of phytoplasma genomes are important, and further identification of virulence factors will help elucidate the pathogenic mechanisms and biology of phytoplasmas.

\section{ACKNOWLEDGMENTS}

This work was supported by the Japan Society for the Promotion of Science (JSPS) through the Funding Program for the Promotion of Science (category "A" of Scientific Research Grant 21248004), and the Funding Program for Next Generation World-Leading Researchers (project: GS005), initiated by the Council for Science and Technology Policy (CSTP).

J. Bacteriol. 188, 3682-3696. doi: 10.1128/JB.188.10.3682-3696.2006 10.1089/dna.2007.0654

Bai, X. D., Correa, V. R., Toruno, T. Y., Ammar, E. D., Kamoun, S., and Hogenhout, S. A. (2009). AY-WB phytoplasma secretes a protein that targets plant cell nuclei. Mol. Plant Microbe Interact. 22, 18-30. doi: 10.1094/MPMI-221-0018

Bai, X. D., Zhang, J. H., Ewing, A. Miller, S. A., Radek, A. J., Shevchenko, D. V., etal. (2006). Living with genome instability: the adaptation of phytoplasmas to diverse environments of their insect and plant hosts.
Barbara, D. J., Morton, A., Clark, M. F., and Davies, D. L. (2002). Immunodominant membrane proteins from two phytoplasmas in the aster yellows clade (chlorante aster yellows and clover phyllody) are highly divergent in the major hydrophilic region. Microbiology 148, 157-167.

Bertaccini, A. (2007). Phytoplasmas: diversity, taxonomy, and epidemiology. Front. Biosci. 12:673-689. doi: $10.2741 / 2092$

Boutareaud, A., Danet, J. L., Garnier, M., and Saillard, C. (2004)
Disruption of a gene predicted to encode a solute binding protein of an $\mathrm{ABC}$ transporter reduces transmission of Spiroplasma citri by the leafhopper Circulifer haematoceps. Appl. Environ. Microbiol. 70, 39603967.

Christensen, N. M., Axelsen, K. B., Nicolaisen, M., and Schulz, A. (2005). Phytoplasmas and their interactions with hosts. Trends Plant Sci. 10, 526-535. doi: 10.1016/ j.tplants.2005.09.008

Christensen, N. M., Nicolaisen, M., Hansen, M., and Schulz, A. (2004). Distribution of phytoplasmas in 
infected plants as revealed by realtime PCR and bioimaging. Mol. Plant Microbe Interact. 17, 1175-1184. doi: 10.1094/MPMI.2004.17.11.1175

Cornelis, G. R., and Van Gijsegem, F. (2000). Assembly and function of type III secretory systems. Annu. Rev. Microbiol. 54, 735-774. doi: 10.1146/annurev.micro.54.1.735

Curkovic Perica, M., Lepedus, H., and Music, M. S. (2007). Effect of indole3-butyric acid on phytoplasmas in infected Catharanthus roseus shoots grown in vitro. FEMS Microbiol. Lett. 268, 171-177. doi: 10.1111/j.15746968.2006.00577.x

Dalbey, R. E., and Kuhn, A. (2000). Evolutionarily related insertion pathways of bacterial, mitochondrial, and thylakoid membrane proteins. Annu. Rev. Cell Dev. Biol. 16, 51-87. doi: 10.1146/annurev.cellbio.16.1.51

Denancé, N., Sánchez-Vallet, A. Goffner, D., and Molina, A. (2013). Disease resistance or growth: the role of plant hormones in balancing immune responses and fitness costs. Front. Plant Sci. 4:155. doi: 10.3389/fpls.2013.00155

Doi, Y., Teranaka, M., Yora, K., and Asuyama, H. (1967). Mycoplasmaor PLT group-like microorganisms found in the phloem elements of plants infected with mulberry dwarf, potato witches' broom, aster yellows or paulownia witches' broom. Ann. Phytopathol. Soc. Jpn. 33, 259-266. doi: 10.3186/ijphytopath. 33.259

Economou, A. (1999). Following the leader: bacterial protein export through the Sec pathway. Trends Microbiol. 7, 315-320. doi: 10.1016/S0966-842X(99)01555-3

Firrao, G., Garcia-Chapa, M., and Marzachi, C. (2007). Phytoplasmas: genetics, diagnosis and relationships with the plant and insect host. Front. Biosci. 12:1353-1375. doi: $10.2741 / 2153$

Glass, J. I., Lefkowitz, E. J., Glass, J. S., Heiner, C. R., Chen, E. Y., and Cassell, G. H. (2000). The complete sequence of the mucosal pathogen Ureaplasma urealyticum. Nature 407, 757-762. doi: 10.1038/35037619

Higgins, C. F. (2001). ABC transporters: physiology, structure and mechanism - an overview. Res. Microbiol. 152, 205-210. doi: 10.1016/S09232508(01)01193-7

Himeno, M., Neriya, Y., Minato, N., Miura, C., Sugawara, K., Ishii, Y., et al. (2011). Unique morphological changes in plant pathogenic phytoplasma-infected petunia flowers are related to transcriptional regulation of floral homeotic genes in an organ-specific manner. Plant J. 67, 971-979. doi: 10.1111/j.1365313X.2011.04650.x

Hogenhout, S. A., Oshima, K., Ammar, E. D., Kakizawa, S., Kingdom, H. N., and Namba, S. (2008). Phytoplasmas: bacteria that manipulate plants and insects. Mol. Plant Pathol. 9, 403-423. doi: 10.1111/j.13643703.2008.00472.x

Hoshi, A., Oshima, K., Kakizawa, S. Ishii, Y., Ozeki, J., Hashimoto, M. et al. (2009). A unique virulence factor for proliferation and dwarfism in plants identified from a phytopathogenic bacterium. Proc. Natl. Acad. Sci. U.S.A. 106, 6416-6421. doi: 10.1073/pnas.0813038106

Jomantiene, R., and Davis, R. E. (2006). Clusters of diverse genes existing as multiple, sequence-variable mosaics in a phytoplasma genome. FEMS Microbiol. Lett. 255, 59-65. doi: 10.1111/j.1574-6968.2005.00057.x

Jomantiene, R., Zhao, Y., and Davis, R. E. (2007). Sequencevariable mosaics: composites of recurrent transposition characterizing the genomes of phylogenetically diverse phytoplasmas. DNA Cell Biol. 26, 557-564. doi: 10.1089/ dna.2007.0610

Jones, J. D. G., and Dangl, J. L. (2006). The plant immune system. Nature 444, 323-329. doi: 10.1038/ nature 05286

Jung, H. Y., Miyata, S. I., Oshima, K., Kakizawa, S., Nishigawa, H. Wei, W., et al. (2003). First complete nucleotide sequence and heterologous gene organization of the two rRNA operons in the phytoplasma genome. DNA Cell Biol 22, 209-215. doi: 10.1089/10445490332 1655837

Kakizawa, S., Oshima, K., Kuboyama, T., Nishigawa, H., Jung, H. Y., Sawayanagi, T., et al. (2001). Cloning and expression analysis of Phytoplasma protein translocation genes. Mol. Plant Microbe Interact. 14, 1043 1050. doi: 10.1094/MPMI.2001.14 9.1043

Kakizawa, S., Oshima, K., Nighigawa, H., Jung, H. Y., Wei, W., Suzuki, S., et al. (2004). Secretion of immunodominant membrane protein from onion yellows phytoplasma through the Sec protein-translocation system in Escherichia coli. Microbiology 150, 135-142. doi: 10.1099/mic.0. 26521-0

Kube, M., Mitrovic, J., Duduk, B., Rabus, R., and Seemuller, E. (2012). Current view on phytoplasma genomes and encoded metabolism. Sci. World J. 2012, 185942. doi: $10.1100 / 2012 / 185942$
Kube, M., Schneider, B., Kuhl, H., Dandekar, T., Heitmann, K. Migdoll, A. M., et al. (2008). The linear chromosome of the plantpathogenic mycoplasma 'Candidatus Phytoplasma mali'. BMC Genomics 9:306. doi: 10.1186/1471-2164-9-306

Lee, I. M., Davis, R. E., and GundersenRindal, D. E. (2000). Phytoplasma: phytopathogenic mollicutes. Annu. Rev. Microbiol. 54, 221-255. doi: 10.1146/annurev.micro.54.1.221

Lee, I. M., Zhao, Y., and Bottner, K. D. (2005). Novel insertion sequencelike elements in phytoplasma strains of the aster yellows group are putative new members of the IS3 family. FEMS Microbiol. Lett. 242, 353-360. doi: 10.1016/j.femsle.2004. 11.036

Lee, I. M., Zhao, Y., and Bottner, K. D. (2006). SecY gene sequence analysis for finer differentiation of diverse strains in the aster yellows phytoplasma group. Mol. Cell. Probes 20, 87-91. doi: 10.1016/j.mcp.2005.10.001

Lim, P. O., and Sears, B. B. (1992). Evolutionary relationships of a plant-pathogenic mycoplasmalike organism and Acholeplasma laidlawii deduced from 2 ribosomal-protein gene-sequences. J. Bacteriol. 174, 2606-2611.

MacLean, A. M., Sugio, A., Makarova, O. V., Findlay, K. C., Grieve, V. M., Toth, R., etal. (2011). Phytoplasma effector SAP54 induces indeterminate leaf-like flower development in Arabidopsis plants. Plant Physiol. 157, 831-841. doi: 10.1104/pp.111.181586

Miura, C., Sugawara, K., Neriya, Y., Minato, N., Keima, T. Himeno, M., et al. (2012). Functional characterization and gene expression profiling of superoxide dismutase from plant pathogenic phytoplasma. Gene 510, 107-112. doi: 10.1016/j.gene.2012.09.001

Miyata, S., Furuki, K., Oshima, K. Sawayanagi, T., Nishigawa, H., Kakizawa, S., etal. (2002). Complete nucleotide sequence of the S10-spc operon of phytoplasma: Gene organization and genetic code resemble those of Bacillus subtilis. DNA Cell Biol. 21, 527-534. doi: 10.1089/104454902320219086

Miyata, S., Oshima, K., Kakizawa, S., Nishigawa, H., Jung, H. Y., Kuboyama, T., et al. (2003). Two different thymidylate kinase gene homologues, including one that has catalytic activity, are encoded in the onion yellows phytoplasma genome. Microbiology 149, 2243-2250. doi: $10.1099 /$ mic.0.25834-0
Moran, N. A. (2002). Microbial minimalism: genome reduction in bacterial pathogens. Cell 108, 583586. doi: 10.1016/S0092-8674(02) 00665-7

Nakai, K., and Kanehisa, M. (1991). Expert system for predicting protein localization sites in gram-negative bacteria. Proteins 11, 95-110. doi: 10.1002/prot.340110203

Namba, S., Oyaizu, H., Kato, S., Iwanami, S., and Tsuchizaki, T. (1993). Phylogenetic diversity of phytopathogenic mycoplasmalike organisms. Int. J. Syst. Bacteriol. 43, 461-467. doi: 10.1099/00207713-433-461

Nielsen, H., Engelbrecht, J., Brunak, S., and vonHeijne, G. (1997). Identification of prokaryotic and eukaryotic signal peptides and prediction of their cleavage sites. Protein Eng. 10, 1-6. doi: 10.1093/protein/10.1.1

Nishigawa, H., Miyata, S., Oshima, K., Sawayanagi, T., Komoto, A., Kuboyama, T., et al. (2001). In planta expression of a protein encoded by the extrachromosomal DNA of a phytoplasma and related to geminivirus replication proteins. Microbiology 147, 507-513.

Oshima, K., Ishii, Y., Kakizawa, S., Sugawara, K., Neriya, Y., Himeno, M., et al. (2011). Dramatic transcriptional changes in an intracellular parasite enable host switching between plant and insect. PLoS ONE 6:e23242. doi: 10.1371/journal.pone.0023242

Oshima, K., Kakizawa, S., Arashida, R., Ishii, Y., Hoshi, A., Hayashi, Y., etal. (2007). Presence of two glycolytic gene clusters in a severe pathogenic line of Candidatus Phytoplasma asteris. Mol. Plant Pathol. 8, 481-489. doi: 10.1111/j.13643703.2007.00408.x

Oshima, K., Kakizawa, S., Nishigawa, H., Jung, H. Y., Wei, W., Suzuki, S., et al. (2004). Reductive evolution suggested from the complete genome sequence of a plant-pathogenic phytoplasma. Nat. Genet. 36, 27-29. doi: $10.1038 / \mathrm{ng} 1277$

Oshima, K., Kakizawa, S., Nishigawa, H., Kuboyama, T., Miyata, S., Ugaki, M., et al. (2001a). A plasmid of phytoplasma encodes a unique replication protein having both plasmidand virus-like domains: Clue to viral ancestry or result of virus/plasmid recombination? Virology 285, 270277. doi: 10.1006/viro.2001.0938

Oshima, K., Shiomi, T., Kuboyama, T., Sawayanagi, T., Nishigawa, H., Kakizawa, S., et al. (2001b). Isolation and characterization of derivative lines of the onion yellows phytoplasma that do not 
cause stunting or phloem hyperplasia. Phytopathology 91, 10241029. doi: 10.1094/PHYTO.2001.91. 11.1024

Oshima, K., Miyata, S., Sawayanagi, T., Kakizawa, S., Nishigawa, H., Jung, H. Y., et al. (2002). Minimal set of metabolic pathways suggested from the genome of onion yellows phytoplasma. J. Gen. Plant Pathol. 68, 225-236. doi: 10.1007/PL0 0013081

Oshima, K., and Nishida, H. (2007). Phylogenetic relationships among mycoplasmas based on the whole genomic information. J. Mol. Evol. 65, 249-258. doi: 10.1007/s00239007-9010-3

Pertot, I., Musetti, R., Pressacco, L., and Osler, R. (1998). Changes in indole-3-acetic acid level in micropropagated tissues of Catharanthus roseus infected by the agent of the clover phyllody and effect of exogenous auxins on phytoplasma morphology. Cytobios 95, 13-23.

Razin, S., Yogev, D., and Naot, Y. (1998). Molecular biology and pathogenicity of mycoplasmas. Microbiol. Mol. Biol. Rev. 62, 1094-1156.

Samuelson, J. C., Chen, M. Y., Jiang, F. L., Moller, I., Wiedmann, M., Kuhn, A., et al. (2000). YidC mediates membrane protein insertion in bacteria. Nature 406, 637-641. doi: 10.1038/35020586

Santana, M., Ionescu, M. S., Vertes, A., Longin, R., Kunst, F., Danchin, A., etal. (1994). Bacillus subtilis F0F1 ATPase - DNA-sequence of the atp operon and characterization of atp mutants. J. Bacteriol. 176, 6802-6811.

Scotti, P. A., Urbanus, M. L., Brunner, J., de Gier, J. W. L., von Heijne, G., van der Does, C., et al. (2000). YidC, the Escherichia coli homologue of mitochondrial Oxalp, is a component of the Sec translocase. EMBO J.
19, 542-549. doi: 10.1093/emboj/19. 4.542

Serek, J., Bauer-Manz, G., Struhalla, G., van den Berg, L., Kiefer, D., Dalbey, R., et al. (2004). Escherichia coli YidC is a membrane insertase for Sec-independent proteins. EMBO J. 23, 294-301. doi: 10.1038/sj.emboj.7600063

Strauss, E. (2009). Phytoplasma research begins to bloom. Science 325, 388-390. doi: 10.1126/science. 325_388

Sugawara, K., Honma, Y., Komatsu, K., Himeno, M., Oshima, K., and Namba, S. (2013). The alteration of plant morphology by small peptides released from the proteolytic processing of the bacterial peptide TENGU. Plant Physiol. 162, 2005-2014. doi: 10.1104/pp.113.218586

Sugio, A., and Hogenhout, S. A. (2012). The genome biology of phytoplasma: modulators of plants and insects. Curr. Opin. Microbiol. 15, 247-254. doi: 10.1016/j.mib.2012.04.002

Sugio, A., Kingdom, H. N., MacLean, A. M., Grieve, V. M., and Hogenhout, S. A. (2011a). Phytoplasma protein effector SAP11 enhances insect vector reproduction by manipulating plant development and defense hormone biosynthesis. Proc. Natl. Acad. Sci. U.S.A. 108, E1254-E1263. doi: 10.1073/pnas. 1105664108

Sugio, A., MacLean, A. M., Kingdom, H. N., Grieve, V. M., Manimekalai, R., and Hogenhout, S. A. (2011b). Diverse targets of phytoplasma effectors: from plant development to defense against insects. Annu. Rev. Phytopathol. 49, 175-195. doi: 10.1146/annurev-phyto-072910095323

Suzuki, S., Oshima, K., Kakizawa, S., Arashida, R., Jung, H. Y., Yamaji, Y., et al. (2006). Interaction between the membrane protein of a pathogen and insect microfilament complex determines insect-vector specificity. Proc. Natl. Acad. Sci. U.S.A. 103, 4252-4257. doi: 10.1073/pnas. 0508668103

Tamas, I., Klasson, L., Canback, B., Naslund, A. K., Eriksson, A. S. Wernegreen, J. J., et al. (2002). 50 million years of genomic stasis in endosymbiotic bacteria. Science 296, 2376-2379. doi: 10.1126/science. 1071278

Tjalsma, H., Bolhuis, A., Jongbloed, J. D. H., Bron, S., and van Dijl, J. M. (2000). Signal peptide-dependent protein transport in Bacillus subtilis: a genome-based survey of the secretome. Microbiol. Mol. Biol. Rev. 64, 515-547. doi: 10.1128/MMBR.64.3.515-547.2000

Toruno, T. Y., Music, M. S., Simi, S., Nicolaisen, M., and Hogenhout, S. A. (2010). Phytoplasma PMU1 exists as linear chromosomal and circular extrachromosomal elements and has enhanced expression in insect vectors compared with plant hosts. Mol. Microbiol. 77, 1406-1415. doi: 10.1111/j.1365-2958.2010.07296.x

Tran-Nguyen, L. T. T., Kube, M., Schneider, B., Reinhardt, R., and Gibb, K. S. (2008). Comparative genome analysis of "Candidatus Phytoplasma australiense" (subgroup tuf-Australia I; rp-A) and "Ca. Phytoplasma asteris" strains OY-M and AY-WB. J. Bacteriol. 190, 3979-3991. doi: 10.1128/JB.01301-07

Urbanus, M. L., Scotti, P. A., Froderberg, L., Saaf, A., de Gier, J. W. L., Brunner, J., et al. (2001). Sec-dependent membrane protein insertion: sequential interaction of nascent FtsQ with SecY and YidC. EMBO Rep. 2, 524-529. doi: 10.1093/embo-reports/kve108

Wei, W., Davis, R. E., Jomantiene, R., and Yan, Z. (2008). Ancient, recurrent phage attacks and recombination shaped dynamic sequence-variable mosaics at the root of phytoplasma genome evolution. Proc. Natl. Acad. Sci. U.S.A. 105, 11827-11832. doi: 10.1073/pnas.0805237105

Wei, W., Kakizawa, S., Jung, H. Y., Suzuki, S., Tanaka, M., Nishigawa, H., et al. (2004). An antibody against the SecA membrane protein of one phytoplasma reacts with those of phylogenetically different phytoplasmas. Phytopathology 94, 683686. doi: 10.1094/PHYTO.2004.94. 7.683

Wernegreen, J. J. (2002). Genome evolution in bacterial endosymbionts of insects. Nat. Rev. Genet. 3, 850861. doi: $10.1038 / \mathrm{nrg} 931$

Conflict of Interest Statement: The authors declare that the research was conducted in the absence of any commercial or financial relationships that could be construed as a potential conflict of interest.

Received: 01 July 2013; accepted: 29 July 2013; published online: 14 August 2013. Citation: Oshima K, Maejima $K$ and Namba S (2013) Genomic and evolutionary aspects of phytoplasmas. Front. Microbiol. 4:230. doi: 10.3389/ fmicb.2013.00230

This article was submitted to Frontiers in Evolutionary and Genomic Microbiology, a specialty of Frontiers in Microbiology. Copyright (C) 2013 Oshima, Maejima and Namba. This is an open-access article distributed under the terms of the Creative Commons Attribution License (CC BY). The use, distribution or reproduction in other forums is permitted, provided the original author(s) or licensor are credited and that the original publication in this journal is cited, in accordance with accepted academic practice. No use, distribution or reproduction is permitted which does not comply with these terms. 